\title{
Crianças ouvintes filhos de pais surdos: adversidades no diálogo familiar
}

\author{
DOI: 10.47224/revista master.v6i11.154
}

Felipe de Oliveira Vitorino
Magda Regina Silva Moura
Ana Raquel Ferreira Borges

e-mail: felipevitorino_97@hotmail.com

\section{Resumo}

Estudos envolvendo aquisição de linguagem em "Children of Deaf Adults" (CODA), filhos de pais surdos, ainda são recentes no Brasil, embora seja o país que possui uma linguagem específica (LIBRAS) para pessoas não ouvintes (SOUZA, 2014). O CODA, geralmente, cresce em meio a duas culturas, bilíngue, e nessa perspectiva, a aquisição da linguagem das crianças torna-se um processo complexo e intrigante. Objetivo: Compreender a dinâmica familiar e a aquisição da Língua Brasileira de Sinais (Libras) concomitante à língua portuguesa falada em crianças sem deficiência auditiva filhos de pais surdos. Considerações: O CODA apresenta risco de comprometimento no rendimento escolar além de desenvolver uma maturidade precoce. Ressalta-se a importância da Atenção primária em saúde e da família na estimulação das potencialidades e monitoramento do desenvolvimento dessas crianças. São necessários novos estudos sobre esse grupo e ações específicas na área da saúde.

Palavras-chave: CODA; Linguagem bimodal; Pais surdos

\begin{abstract}
Studies involving language acquisition in "Children of Deaf Adults" (CODA), children of deaf parents, are still recent in Brazil, although it is the country that has a specific language (LIBRAS) for non-hearing people (SOUZA, 2014). CODA generally grows between two cultures, bilingual and in this perspective, the acquisition of children's language becomes a complex and intriguing process. Objective: Understand Family dinamics and the acquisition of the Brazilian Sign Language (Libras) concomitant with the Portuguese language spoken in children without hearing impairment children of deaf parents. Considerations: CODA presents a risk of compromising school performance, in addition to developing early maturity. The importance of Primary Health Care and the family is emphasized in stimulating the potential and monitoring the development of these children. Further studies on this group and specific actions in the health area are need.
\end{abstract}

Keywords: $\quad$ CODA; bimodal language; Deaf parents

\section{INTRODUÇÃO}

Embora o Brasil seja um país que possui uma linguagem específica (LIBRAS) para pessoas não ouvintes, estudos envolvendo filhos de pais surdos embora crescentes na literatura, ainda são escassos (SOUZA, 2014). É incomum famílias em que os filhos são ouvintes com pais surdos. Os "Children of Deaf Adults" (CODA) traduzido no Brasil por "filhos de pais surdos", representam um grupo híbrido, de linguagem bimodal, e têm um papel importante na inclusão do surdo na sociedade, uma vez que conhecem as duas culturas. O CODA, geralmente, cresce em meio a duas culturas, bilíngue e em contato com experiências mais visuais, diferentemente de outras crianças que são filhos de pais ouvintes.

Sabe-se que os indivíduos bilíngues em mais tenra idade aprimoram a sensibilidade ao idioma utilizado por seus interlocutores em idade precoce, e dessa maneira, uma criança experimenta influência na aquisição de cada idioma, na dependência direta de seu interlocutor.

Sob essa perspectiva, a aquisição de linguagem nessa situação é um fato intrigante. Quando categorizada como um aprendizado bilíngue bimodal, por ter a aquisição de uma língua não verbal e uma verbal, torna-se ainda mais complexa e interessante. Alguns aspectos no contexto do discurso e domínio consonante da linguagem na coletividade podem interferir no grau de 
diferenciação da língua na idade pré-escolar dessas crianças. Desse modo, os pais surdos ao mediar o acesso para a língua falada de maneiras variadas, transforma esse processo numa dinâmica cotidiana familiar bem específica.

A partir do momento que os filhos de pais surdos entram em contato com a sociedade e, sobretudo com o ambiente escolar, ainda que não sejam pessoas com deficiência no aprendizado da língua portuguesa, permanecem em uma condição de trânsito entre o universo surdo e ouvinte, necessitando de atenção específica da sociedade. Mas dessa forma, o desenvolvimento da linguagem e o aprendizado tornam-se bidirecionados facilitando a aquisição bilíngue, verbal e não verbal, pela criança.

Esse estudo tem como objetivo compreender a dinâmica familiar e a aquisição da Língua Brasileira de Sinais (LIBRAS) concomitante à língua portuguesa falada em crianças sem deficiência auditiva filhos de pais surdos.

Trata-se de um relato de experiência de contato de discentes universitários com um núcleo familiar constituído por duas crianças ouvintes com linguagem bimodal, e pai e mãe surdos. Após o contato casual em atendimento das crianças na Unidade de Atenção básica a Saúde, surgiu o interesse em entender o papel das crianças na dinâmica familiar. Foi solicitado o consentimento dos pais e aplicado um questionário semiestruturado com informações referentes a dados demográficos, condições de moradia idade dos participantes, grau de parentesco, relações familiares e escolares. Quanto à entrevista sobre a trajetória de aquisição da linguagem bimodal, foi optado por ser semiestruturada com o intuito de permitir uma flexibilidade nas respostas, embora dirigida com foco nos objetivos do estudo.

\section{DESCRIÇÃO DO CASO}

Trata-se de uma família constituída por 4 pessoas, pai de 41 anos de idade, mãe de 37 anos de idade e dois filhos do sexo masculino nascidos em 2009 e 2010 respectivamente. De acordo com os registros de prontuários da rede pública de saúde, as crianças apresentam crescimento adequado à idade cronológica. A mãe e o pai são surdos, sendo a mãe portadora de hipertensão arterial crônica. A entrevista semiestruturada com a mãe e o pai com foco nas inter-relações da família, foram relatadas do nascimento até a data atual, com o intermediário de intérprete de libras.

Após o nascimento e durante os primeiros dias de vida das crianças, a mãe contou com a ajuda dos avós que não têm deficiência auditiva. As crianças iniciaram a formação da sua linguagem, semelhante a toda criança ouvinte, por imitação das palavras dos adultos ouvintes da família. Nesse sentido, a partir do seguimento de aprendizagem da linguagem pelas crianças, pôde-se observar que elas gesticulavam sinais em Libras e palavras em português no decorrer do amadurecimento. Mesmo sendo ouvintes, iniciaram o decurso de aprendizagem da fala pela Língua de Sinais e posteriormente desenvolveram-na quase concomitante a língua portuguesa falada.

Pelo fato de os pais serem surdos e outros membros da família serem ouvintes, as crianças conviveram em um ambiente com pessoas surdas e pessoas ouvintes, e dessa forma aprenderam a linguagem verbal e a não verbal. Dessa forma, aprenderam as duas linguagens e adquiriram o domínio das duas línguas concomitante, no mesmo período.

Atualmente as crianças frequentam a escola de forma irregular, influenciadas pela baixa escolaridade familiar dos pais que não valorizaram a educação formal na escola. Outro aspecto observado é que as duas crianças do estudo têm autonomia e são predominantes tomadoras de decisão em vários aspectos da dinâmica familiar. Pelo fato de ambas não possuírem deficiência auditiva, invariavelmente assumem o papel de tradutores dos pais, tornando-se protagonistas na relação social da família com o serviço de saúde e na sociedade.

\section{DISCUSSÃO}

CODA é um termo de origem inglesa, como explicam Streiechen e Krausf-Lemke (2013), que se refere à expressão Children of Deaf Adults que se traduz como "filhos de pais surdos" ou "filhos (as) de surdos adultos", assim como as crianças do estudo. São observados alguns questionamentos na literatura a respeito de crianças nessa condição. Dentre eles destaca-se o impacto negativo no seu desenvolvimento, as dificuldades no convívio social 
bem como prejuízos na sua saúde, considerando que são poucas as unidades de atenção primária de saúde que dispõem de um intérprete para consultas ou que têm profissionais capacitados fluentes em LIBRAS para atendimento adequado às famílias de CODA (SILVA, 2017).

Os achados encontrados frente essa família, não são diferentes, quando há a constatação da baixa escolaridade dos pais, a constante evasão escolar dessas crianças e a grande quantidade de comorbidades que os pais apresentam, levando aos questionamentos a respeito da integridade da saúde das crianças, com respeito ao desenvolvimento neuropsicomotor geral, do aprendizado da língua portuguesa, bem como da vida social e educacional dessas crianças.

Em concordância com a literatura científica, ao nascer numa família com pais surdos a primeira língua que a criança terá contato será a língua gestual (ALMEIDA, 2007), como foi o caso dessas crianças do estudo.

No entanto, com a convivência social, seja pelo próprio aprendizado com os irmãos, ou outros familiares não surdos, os CODA se tornam bilíngues (SILVA, 2017), o que também se aplica às crianças desse estudo, que aprenderam a língua portuguesa com os avós ouvintes. Isto, muitas vezes, faz com que essas crianças sejam intérpretes dos pais, como ocorreu em algumas das visitas domiciliares pela equipe da Unidade Básica de Saúde da Família.

$\mathrm{Na}$ impossibilidade do acompanhamento de um intérprete em LIBRAS, foram as próprias crianças que traduziram e relataram os sintomas da mãe, na condição de paciente durante o atendimento da equipe de saúde. Foi observado ainda que, várias das suas informações eram de sua própria percepção sobre as necessidades dos pais, o que mostra um desenvolvimento de maturidade precoce.

Para Melo (2015), as crianças CODA se desenvolvem com maior maturidade e senso crítico justamente por perceberem e analisarem os momentos e circunstâncias convenientes às transições linguísticas.

Quanto ao desenvolvimento educacional, a literatura registra que, a prática da LIBRAS não afeta o desempenho escolar dos CODA, como afirmam pais e professoras, o desenvolvimento da criança CODA se mostra livre de problemáticas, principalmente no que se refere às perspectivas curriculares e comportamentais (MELO, 2015). Porém, devido à grande prevalência de baixo nível de escolaridade dos surdos, é comum que a participação dos pais na vida escolar dos filhos não seja efetiva e não estimule a presença das crianças no ambiente escolar, como constatado nessa família.

De acordo com o Ministério da Educação, em 2013, 59 mil crianças surdas estavam matriculadas na Educação Infantil, 614 mil no Ensino Fundamental e apenas 48 mil no Ensino Médio. Desse modo é grande o número de pessoas, assim como os pais das crianças relatadas no estudo, que não têm o ensino fundamental completo. Segundo Neri (2009), esse fato frequentemente influencia, na educação das crianças, quanto maior a escolaridade do chefe da família, maior a taxa de matrículas dos filhos nas escolas regulares. Em relação à escolaridade dos CODA, verificou-se, no estudo de Silva (2017), que pouco mais de metade da amostra (57\%) apresentava o ensino superior, aproximadamente $28 \%$ completam o ensino médio e $14 \%$ o ensino básico até ao 9. ano. Dessa forma, configura-se como um fator de risco educacional, com grande possibilidade de evasão escolar desse grupo.

Assim, os CODA vivenciam uma experiência adversa à realidade da maioria das crianças filhas de pais ouvintes, permanecendo imersos e divididos em duas culturas, duas línguas, com diferentes respostas aos diferentes estímulos. No entanto, as crianças do estudo negaram dificuldade no relacionamento com outras crianças no ambiente escolar, bem como nas relações sociais dos pais no convívio com outros familiares. Acredita-se que o fato da maioria dos demais familiares serem ouvintes, facilite esse processo de socialização dessas crianças.

Dentro dessa dinâmica familiar, foi observado preocupação dos avós e tios próximos, que acompanham diariamente o desenvolvimento das crianças. Aos olhos do ouvinte, a pessoa surda foge ao padrão de normalidade, segregados pela língua e cultura diferentes, os surdos são vistos somente pela falta de algo, nesse caso, a audição.

O que não se observa, contudo, é que essas crianças adquirem novas habilidades, linguagem e cultura, de forma natural e cotidiana. Logo, ser CODA "é crescer em meio a essa dita diferença, é viver em um contexto visual e linguístico que não é vivenciado 
por crianças ouvintes, filhos de pais ouvintes." (SILVA, 2019)

\section{CONSIDERAÇÕES FINAIS}

Observa-se com o estudo dessa dinâmica familiar que o CODA apresenta risco de comprometimento no rendimento escolar além de uma maturidade precoce. O que demonstra a importância e a necessidade da participação dos serviços de Atenção primária em saúde junto à família do CODA com objetivo de monitorar a saúde mental e o desenvolvimento dessas crianças.

É fundamental que os pais e a família adquiram a consciência do potencial dessas crianças na aquisição de maturidade, do senso crítico e da autonomia já desenvolvida, e continuem no processo de estimulação nas diversas áreas de aprendizagem.

A literatura explora bem o tema de filhos de pais surdos nas áreas da pedagogia e fonoaudiologia, contudo, existem poucas pesquisas e atualizações na área da saúde. Portanto, se fazem necessários mais estudos a respeito do processo de desenvolvimento dos CODA especialmente na área da saúde, considerando a sobrecarga de responsabilidade assumida frente às necessidades dos pais nas suas relações sociais e pessoais.

\section{5}

\section{REFERÊNCIAS}

ALARCÃO, M. (Des)Equilíbrios Familiares. Coimbra: Edições Quarteto, 2000.

ALMEIDA, M. A criança surda e o desenvolvimento da literária. 2007. Dissertação (Mestrado) Universidade de Aveiro/Escola Superior de Educação de Setúbal, Portugal, 2007.

AZENHA, S. Desenvolvimento Linguístico da criança ouvinte com pais surdos. Mestrado (Educação Pré-Escolar) - Escola Superior de Educação Jean Piaget, Campus Universitário de Almada, 2018

CARDOSO, L.; TAVARES, Y.; DA SILVA, M. Ensino de língua portuguesa como segunda língua: o caso dos alunos surdos no ensino médio no município de Guimarães/MA. Littera on line, v. 9, n. Esp., 2018.

CRUZ, C. R.; FINGER, I. Aquisição fonológica do português brasileiro por crianças ouvintes bilíngues bimodais e surdas usuárias de implante coclear. Let Hoje, v. 48, no 3, p. 389-398, 2013.

Fernández-Viader, M. El Valor de la Mirada: Sordera y Educación. Barcelona: Publicacions i Edicions Universitat de Barcelona, 2004.

LILLO-MARTIN, D et al. Language choice in bimodal bilingual development. Frontiers in Psychology, v. 5, p. 1163, 2014.

MELO, N. Uma ouvinte entre mundos: A criança filha de pais surdos, suas interações linguísticas e os potenciais da aquisição da língua de sinais. Trabalho Final de Curso (Licenciatura em pedagogia) - Universidade de Brasília- UnB Faculdade de Educação - FE, [S. I.], 2015.

MINISTERIO DA EDUCAÇÃO. Política Nacional de Educação Especial na Perspectiva da Educação Inclusiva. Disponível em:

http://portal.mec.gov.br/index.php?option=com_d ocman\&view=download\&alias=1669 0-politicanacional-de-educacao-especial-na-perspectiva-daeducacao-inclusiva05122014\&Itemid=30192.

Acesso em: março de 2020.

MOREIRA, V. Inclusão educacional de surdos uma questão social. Trabalho de Conclusão de Curso (Especialização em Gestão e Políticas Públicas) Fundação Escola de Sociologia e Política de São Paulo, [S. I.], 2014.

NERI, M. Motivos da evasão escolar. 1. ed. FGV Repositório Digital: FGV, 36 p, 2009.

PEREIRA, O. R. Nascidos no silêncio: as relações entre filhos ouvintes e pais surdos na educação. Dissertação de (mestrado em educação). Faculdade de Humanidades e Direito da Universidade metodista de São Paulo. São Bernardo do Campo, 2013.

SILVA, M. Experiências de Filhos Ouvintes com Pais Surdos nas Dimensões: Familiar, Social e Educativa. Mestrado (ESE - DPRM - Educação Especial: Multideficiência e Problemas de Cognição) 
- Instituto Politécnico do Porto. Escola Superior de Educação, [S. I.], 2017.

SILVA, M. O Coda, filhos ouvintes de pais surdos, e a Tradução e Interpretação de Libras: 0 que encontramos? Belas Infiéis, v. 8, n. 1, p. 37-53, 2019. DOI: 10.26512/belasinfieis.v8.n1, 2019.

SOUSA, A. N.; QUADROS, R. M. Uma análise do fenômeno "alternância de línguas" na fala de bilíngues intermodais (Libras e português). Revista Virtual Estudos da Linguagem, v. 10, no 19, p. 329346, 2012.

SOUZA, J. Intérpretes codas: Construção de identidades. Dissertação (Mestrado em Tradução) - Centro de Comunicação e Expressão, Universidade Federal de Santa Catarina, Florianópolis, 2014.

STREIECHEN, E. M.; KRAUSE-LEMKE, C. A aquisição da Libras por crianças ouvintes filhas de mãe surda num contexto multilíngue. Seminário de Pesquisa do Programa de Pós-Graduação em Educação, 12, Maringá, 2013. Anais Maringá: UEM, p. 1-19, 2012.

VARGAS, D. Z.; MEZZOMO, C. L.; KESSLER, T. M. 0 desenvolvimento da percepção dos contrastes mínimos na Língua Brasileira de Sinais em um grupo de codas. Revista CEFAC, v. 18, no 4, p. 835842, jul.-ago. 2016. 